\title{
Air quality at venues of mixed smoking policies in Kazakhstan
}

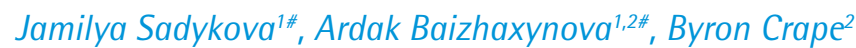

\begin{abstract}
INTRODUCTION Enclosed designated smoking areas (DSAs) and smoking zones are allowed in food-serving venues in Kazakhstan. Air quality in smoke-free foodserving venues, in venues with smoking throughout, in those with DSAs and those with smoking zones, is not fully understood.

METHODS A cross-sectional study with aim to evaluate $\mathrm{PM}_{2.5}$ concentrations in the venues with mixed smoking was conducted from September to October 2017 in Almaty, the largest city of Kazakhstan. A total of 44 rooms within the selected 29 venues were evaluated: $100 \%$ smoke-free (5), non-smoking zones (7), smoking zones (7), non-smoking venues with DSAs (8), venues that allow smoking throughout (9), and DSAs (8). Real-time $\mathrm{PM}_{2.5}$ measurement was conducted by TSI SidePak AM510 Personal Aerosol Monitor and used to rank health-risk assessment using the Air Quality Index developed by the U.S. Environmental Protection Agency.

RESULTS Smoke-free food-serving venues had moderate levels of air quality with mean $\mathrm{PM}_{2.5}$ of $26.2 \mathrm{\mu g} / \mathrm{m}^{3}$ while non-smoking zones inside venues that also permitted smoking had a mean of $56.5 \mu \mathrm{g} / \mathrm{m}^{3}$, corresponding to unhealthy air quality. Venues restricting smoking only to DSAs also had unhealthy air quality in non-smoking areas $\left(\right.$ mean $\mathrm{PM}_{2.5}=87.6 \mu \mathrm{g} / \mathrm{m}^{3}$ ) while DSAs had hazardous levels of air quality (mean $\mathrm{PM}_{2.5}=647.9 \mathrm{\mu g} / \mathrm{m}^{3}$ ). Smoking zones inside the venues and venues allowing smoking throughout had a mean $\mathrm{PM}_{2.5}$ of 180.3 and $182.0 \mu \mathrm{g} / \mathrm{m}^{3}$, respectively, ranking as very unhealthy. On average 3.5 persons were observed in DSAs with mean volume of $38.9 \mathrm{~m}^{3}$. Cigarette and/or hookah were the major source of $\mathrm{PM}_{2.5}$. The higher the smoker density the poorer the air quality in the venue.

Conclusions Hazardous level of $\mathrm{PM}_{2.5}$ due to tobacco products inside DSAs demonstrated the low efficiency of a smoking ban with exemptions. A complete smoking ban in food-serving venues should be in place to fully protect people from hazardous air quality conditions.
\end{abstract}

\author{
AFFILIATION \\ 1 National Coalition 'Smoke- \\ free Kazakhstan', Nur-Sultan, \\ Kazakhstan \\ 2 Public Health Program, \\ School of Medicine, \\ Nazarbayev University, Nur- \\ Sultan, Kazakhstan \\ \#Co-correspondence authors \\ CORRESPONDENCE TO \\ Jamilya Sadykova. National \\ Coalition 'Smoke-free \\ Kazakhstan', 25 Kenesary \\ Street, Nur-Sultan, \\ Kazakhstan. E-mail: \\ dzhamilya75@mail.ru \\ ORCID ID: https://orcid. \\ org/0000-0001-9777-5643 \\ Ardak Baizhaxynova. \\ National Coalition 'Smoke- \\ free Kazakhstan', 25 \\ Kenesary Street, Nur-Sultan, \\ Kazakhstan. E-mail: ardak. \\ baizhaxynova@nu.edu.kz \\ ORCID ID: https://orcid. \\ org/0000-0002-0956-6743 \\ KEYWORDS \\ designated smoking areas, \\ smoking policy, air quality, \\ Kazakhstan \\ Received: 18 May 2020 \\ Revised: 24 August 2020 \\ Accepted: 3 September 2020
}

\section{INTRODUCTION}

Secondhand smoke (SHS) is a combination of sidestream (smoke emitted from the tobacco stick) and mainstream smoke (smoke ex-haled by a person), resulting in the production of numerous gasses and particulate matter ${ }^{1}$. The International Agency for Research on Cancer stated that SHS exposure has a cancerogenic nature ${ }^{2-4}$. SHS exposure increases risk of developing a range of serious illnesses, including lung cancer, cardiovascular disease, respiratory disease, and asthma. Other significant health outcomes such as eye irritation, nasal inflammation, and low birthweight are caused by secondhand smoke exposure ${ }^{1}$. In the post-Soviet and former pro-Soviet block countries of Estonia, Hungary, Latvia, Lithuania, Moldova, Russia, Belarus, Ukraine, and Kazakhstan, it is estimated that $61.0 \%$ of non-smoking children and $66.0 \%$ of non-smoking men and women are exposed to SHS 
in public places. In 2004, it is estimated that 99300 deaths resulted from exposure to SHS in the region ${ }^{5}$. A national tobacco study estimated that $22.9 \%$ adults smoke $^{6}$ and $27.6 \%$ of adults are exposed to SHS in public eating places (bars, restaurants, cafés) in Kazakhstan ${ }^{7}$.

Article 159 of the Kazakhstan Health Act of 2009, despite being obliged by Article 8 of the World Health Organization's Framework Convention on Tobacco Control to ban smoking in public areas, allows for designated smoking areas (DSAs) where food is served, if the owner chooses ${ }^{8}$, despite evidence that designated smoking areas do not protect non-smokers from SHS exposure ${ }^{9,10}$. Thus, Almaty, the largest city of Kazakhstan, has public eating venues with a diverse range of smoking restrictions including: venues with smoking and non-smoking zones, smoking allowed throughout the venue, completely smoke-free venues, and smoke-free venues with DSAs.

The goal of this study was to assess and compare air quality in public food-serving venues of Almaty with different smoking regulations by measuring indoor $\mathrm{PM}_{2.5}$ levels. Particularly, we aimed at analyzing whether separation of smokers and non-smokers by rooms/zones or by special designated smoking areas could protect people from SHS. The objectives were to: 1) measure and compare $\mathrm{PM}_{25}$ levels between non-smoking zones in venues (that permit smoking in separate smoking zones) to $100 \%$ smoke-free food-serving venue, 2) measure and compare $\mathrm{PM}_{2.5}$ levels in DSAs that are located in food-serving venues with venues where smoking is allowed throughout, and 3) evaluate the association of $\mathrm{PM}_{2.5}$ levels with smoker density. To the best of our knowledge, there are no published studies in post-Soviet countries with transitional economies that evaluated levels of $\mathrm{PM}_{2.5}$ in venues with different smoke-free policies, increasing the importance of the study.

\section{METHODS}

For the current study, we utilized the Air Quality Index (AQI) of the U.S. Environmental Protection Agency (EPA) for linking $\mathrm{PM}_{2.5}$ with air quality, based on health impacts ${ }^{11}$. $\mathrm{PM}_{2.5}$ levels were measured using the TSI SidePak AM510 Personal Aerosol Monitor - a validated tool for real-time measuring of $\mathrm{PM}_{2.5}$ levels every minute ${ }^{12-16}$. Although our results express 30 minutes exposure values, the EPA AQI provides a good reference standard.

The study of food-serving venue facilities did not require approval because it did not include human study participants and was not considered human subject research. Only facility internal structures, counts of burning tobacco, and environmental particulate matter measurements were recorded.

\section{Venue selection}

The indoor air quality monitoring study was conducted from September to October 2017 in the city of Almaty, Kazakhstan. A total of 29 restaurants, cafes, and bars were selected from a list of popular food-serving venues in the densest areas in each of the 8 administrative regions of Almaty ${ }^{17}$ and coded by the numbers and first letters. Researchers previously assessed smoking restrictions and peak hours of operation by phone for each venue. Three to four venues from each region were selected for the study.

At least two venues from each district were selected. Among the 29 venues, 5 were $100 \%$ smokefree, 15 had mixed smoking policies (smoking and non-smoking zones, or separate designated smoking areas) and 9 allowed smoking throughout the venue. The research team included a Campaign for TobaccoFree Kids trainer and volunteers from the Kazakhstan Smoke-free coalition who selected the venues using criteria that included the venue's smoking policy, peak hours of operation and average number of customers.

\section{Materials}

The interior dimensions of the venues were measured using a Zircon DM 840 laser. Because some foodserving venues have different wall shapes, the volumes of venues were calculated based on laser measurements. The volume of some venues was more difficult to calculate due to their odd-shaped interior walls and ceilings and therefore were calculated separately using specialized diagrams. This approach has been used in similar studies ${ }^{12,15,16,18}$.

\section{Data collection}

A total of 29 venues were observed during the research period. According to the type of venue smoking policies and room selection, rooms were divided into six types: $100 \%$ smoke free (SF), smoking throughout the venue (SV), non-smoking rooms with designated areas for smokers (NR), designated areas 
for smokers (DSA), venues that allow smoking zones (SZ), and non-smoking zones (NZ). The last category usually did not have a door or any separation between rooms for smokers and non-smokers.

A researcher from the Campaign for Tobacco-Free Kids operated the SidePak AM510 Personal Aerosol Monitor and measured the volume of the room by utilizing a laser. A trained person as data collector counted the number of smokers. Air for analysis was collected through a Tygon tubing that was connected to the AM510. Researchers did a thorough walk-through each venue. Food-serving venues are busiest on weekends at late evening hours, so the data collectors visited venues on Thursdays, Fridays, Saturdays and Sundays from 7 pm until midnight.

Before data collection inside the venue, $\mathrm{PM}_{2.5}$ exposure was evaluated for 5 min outside the building. Data were collected inside the venue for at least 30 min, and outside the venue for $5 \mathrm{~min}$. If a venue had smoking and non-smoking rooms, data were collected for $30 \mathrm{~min}$ in each room. Between each room type, the recalibration was done during 5 min outside the building.

Data collection was incognito, no one was approached inside the venue. Researchers purchased food and drinks in the venue. The SidePak AM510 was carried in a small handbag, and inconspicuously was left on the shoulder or on a table near the researcher. For each venue the name of the venue, type of venue, time of entry and exit, the volume of the room, the number of people and counts of burning cigarettes and hookahs taken in 15-minute intervals, and other possible sources of $\mathrm{PM}_{2.5}$ such as lit candles or fumes from the kitchen were recorded.

\section{Data analysis}

For the analysis, each room type in the venue was utilized as a separate unit of analysis. According to the division of food-serving venues by smoking policies and rooms, six room types were analyzed: SF (100\% smoke free - where smoking is strictly prohibited), SV (smoking allowed throughout the venue), SZ (smoking zone inside the venue) and NZ (nonsmoking zones inside the venue), NR (non-smoking room in venue with DSA), and DSA (designated areas for smokers).

The average smoker density was calculated by taking the mean number of burning tobacco products per $100 \mathrm{~m}^{3}$. Burning tobacco products included both cigarettes and hookahs. No electronic cigarettes were observed in the selected venues. The mean number of burning tobacco products (mean number of people smoking) inside a room was estimated by counting the number of burning tobacco products at the start of the observation period, and at 15 minutes and 30 minutes later. The sum of tobacco burning products per $\mathrm{m}^{3}$ was divided by three to calculate the mean. The measurements for SidePak AM510 were made by excluding the first and the last minute of the $\mathrm{PM}_{2.5}$ data for each venue, while adjusting for the calibration factor of $0.32^{18-20}$.

Analysis was conducted using the STATA SE/12.0 software package. Non-parametric tests were applied due to small sample size and lack of normality. The Kruskal-Wallis test was utilized to assess whether the mean $\mathrm{PM}_{2.5}$ concentration levels across room types differed. To determine differences for median $\mathrm{PM}_{2.5}$ concentrations, eight comparison groups for room types were analyzed. The Wilcoxon signed rank test was conducted for comparing rooms (NR and DSA; SZ and NZ) and Mann-Whitney U test for venues (SZ and DSA; NZ and NR; SF and NZ; SF and NR; SV and SZ; SV and DSA). The association between the mean smoker density and mean $\mathrm{PM}_{2.5}$ concentrations were explored using the Spearman correlation. All tests were conducted with an a value of 0.05 .

\section{RESULTS}

A total of 44 rooms within the selected 29 venues were included in the analysis. The results are presented in Table 1, for descriptive variables including: the volume of the venue, the mean smoker density, the mean $\mathrm{PM}_{2.5}$ concentration, the venue's smoking policy, and the type of room.

The mean customer occupancy of a room varied from 1 to 78 people. Non-smoking rooms (NR) that had separate areas for smoking (DSAs) were the most crowded, with a mean of 41.4 persons per room, followed by smoking venues with 24.6 persons per room and smoke-free venue with 18.2 persons per room. Non-smoking and smoking zones inside venues had almost the same occupancy with 12.6 and 11.6 persons per room, respectively. A mean of 3.5 persons was observed in DSAs, which had an average size of $38.9 \mathrm{~m}^{3}$. No tobacco product use was observed in smoke-free venues and non-smoking zones. Smoking 
Table 1. Descriptive statistics and $P M_{2.5}$ concentrations for each venue by room smoking status

\begin{tabular}{|c|c|c|c|c|c|c|}
\hline Venue name & $\begin{array}{c}\text { Type of } \\
\text { room }\end{array}$ & $\begin{array}{l}\text { Venue size } \\
\qquad\left(\mathrm{m}^{3}\right)\end{array}$ & $\begin{array}{l}\text { Mean } \\
\text { number of } \\
\text { people }\end{array}$ & $\begin{array}{l}\text { Mean tobacco } \\
\text { burning } \\
\text { products }\end{array}$ & $\begin{array}{c}\text { Mean PM } \\
\quad\left(\mu g / m^{3}\right)\end{array}$ & $\begin{array}{c}\text { Mean smoker } \\
\text { density (mean } \\
\text { burning product } \\
\text { per } 100 \mathrm{~m}^{3} \text { ) }\end{array}$ \\
\hline
\end{tabular}

SF: Smoke-free (smoking is strictly prohibited)

$\begin{array}{lrrrrrr}1 \text { CV } & \text { SF } & 76.8 & 2.0 & 0 & 13.8 & 0 \\ 2 \text { St } & \text { SF } & 377.2 & 22.0 & 0 & 3.5 & 0 \\ 3 \mathrm{CT} & \mathrm{SF} & 642.6 & 41.3 & 0 & 0 & 0 \\ 4 \mathrm{MS} & \mathrm{SF} & 77.0 & 7.3 & 0 & 17.3 & 0 \\ 5 \mathrm{RBG} & \mathrm{SF} & 476.0 & 18.3 & 0 & 33.0 & 0 \\ \text { Average } & \mathrm{S} & 330.0 & 18.2 & 0 & 26.2 & 0\end{array}$

NZ: Non-smoking zone of the venue (venue has smoking and non-smoking zones)

\begin{tabular}{|c|c|c|c|c|c|c|}
\hline $6 \mathrm{NB}$ & $\mathrm{NZ}$ & 72.9 & 6.6 & 0 & 51.1 & 0 \\
\hline $7 \mathrm{Tu}$ & $\mathrm{NZ}$ & 495.0 & 12.0 & 0 & 91.1 & 0 \\
\hline $8 \mathrm{RJ}$ & $\mathrm{NZ}$ & 126.0 & 13.0 & 0 & 70.9 & 0 \\
\hline $9 \mathrm{MZ}$ & $\mathrm{NZ}$ & 54.0 & 13.3 & 0 & 75.4 & 0 \\
\hline $10 \mathrm{Ve}$ & $\mathrm{NZ}$ & 115.2 & 11.0 & 0 & 32.8 & 0 \\
\hline 11 Lo & $\mathrm{NZ}$ & 312.0 & 16.3 & 0 & 51.2 & 0 \\
\hline $12 \mathrm{Mo}$ & $\mathrm{NZ}$ & 544.5 & 9.3 & 0 & 22.7 & 0 \\
\hline Average & & 245.6 & 11.6 & 0 & 56.5 & 0 \\
\hline
\end{tabular}

SZ: Smoking zone of the venue (venue has smoking and non-smoking zones)

\begin{tabular}{|c|c|c|c|c|c|c|}
\hline $6 \mathrm{NB}$ & $\mathrm{SZ}$ & 186.2 & 11.3 & 0.6 & 258.5 & 0.4 \\
\hline $7 \mathrm{Tu}$ & $\mathrm{SZ}$ & 742.5 & 19.0 & 2.6 & 315.1 & 0.4 \\
\hline $8 \mathrm{RJ}$ & $\mathrm{SZ}$ & 79.8 & 4.0 & 1.6 & 133.6 & 2.1 \\
\hline $9 \mathrm{MZ}$ & $\mathrm{SZ}$ & 102.5 & 13.0 & 2.6 & 285.2 & 2.6 \\
\hline $10 \mathrm{Ve}$ & $\mathrm{SZ}$ & 103.3 & 7.0 & 0.3 & 55.9 & 0.3 \\
\hline 11 Lo & SZ & 124.2 & 5.3 & 2.6 & 183.9 & 2.2 \\
\hline $12 \mathrm{Mo}$ & $\mathrm{SZ}$ & 544.5 & 29.0 & 1.3 & 42.0 & 0.2 \\
\hline Average & & 269.0 & 12.6 & 1.7 & 182.0 & 1.2 \\
\hline \multicolumn{7}{|c|}{$\begin{array}{l}\text { SV: Smoking is allowed throughout the } \\
\text { venue }\end{array}$} \\
\hline $13 \mathrm{LIH}$ & SV & 995.2 & 78.0 & 5.6 & 119.6 & 0.6 \\
\hline 14 Ko & SV & 155.1 & 16.0 & 5.3 & 581.8 & 3.4 \\
\hline 15 Bo & SV & 665.8 & 8.0 & 2.6 & 47.4 & 0.4 \\
\hline 16 NS & SV & 270.0 & 23.0 & 1.6 & 65.2 & 0.6 \\
\hline $17 \mathrm{Zh}$ & SV & 360.0 & 33.3 & 4.6 & 178.3 & 1.3 \\
\hline 18 ZK & SV & 90.0 & 8.6 & 1.6 & 183.9 & 1.9 \\
\hline 19 Do & SV & 396.0 & 5.0 & 0.6 & 103.5 & 0.2 \\
\hline 20 Te & SV & 753.7 & 24.6 & 6.3 & 115.3 & 0.8 \\
\hline $21 \mathrm{Ni}$ & SV & 551.0 & 24.6 & 3.0 & 227.5 & 0.5 \\
\hline Average & & 470.8 & 24.6 & 3.5 & 180.3 & 1.1 \\
\hline
\end{tabular}


Table 1. Continued

\begin{tabular}{|c|c|c|c|c|c|c|}
\hline Venue name & $\begin{array}{l}\text { Type of } \\
\text { room }\end{array}$ & $\begin{array}{c}\text { Venue size } \\
\left(\mathrm{m}^{3}\right)\end{array}$ & $\begin{array}{l}\text { Mean } \\
\text { number of } \\
\text { people }\end{array}$ & $\begin{array}{l}\text { Mean tobacco } \\
\text { burning } \\
\text { products }\end{array}$ & $\begin{array}{l}\text { Mean } \mathrm{PM}_{2.5} \\
\left(\mu \mathrm{g} / \mathrm{m}^{3}\right)\end{array}$ & $\begin{array}{l}\text { Mean smoker } \\
\text { density (mean } \\
\text { burning products } \\
\text { per } 100 \mathrm{~m}^{3} \text { ) }\end{array}$ \\
\hline \multicolumn{7}{|c|}{$\begin{array}{l}\text { NR: Non-smoking room of the venue with } \\
\text { DSA }\end{array}$} \\
\hline 22 Ro & NR & 434.8 & 9.3 & 0 & 67.5 & 0 \\
\hline $23 \mathrm{Al}$ & NR & 1174.7 & 55.3 & 0 & 78.3 & 0 \\
\hline $24 \mathrm{FV}$ & NR & 1926.4 & 123.0 & 0 & 144.4 & 0 \\
\hline $25 \mathrm{Ba}$ & NR & 217.0 & 33.6 & 0 & 20.6 & 0 \\
\hline $26 \mathrm{Gu}$ & NR & 195.0 & 19.3 & 0 & 33.2 & 0 \\
\hline $27 \mathrm{Ko}$ & NR & 465.5 & 16.6 & 0 & 66.7 & 0 \\
\hline $28 \mathrm{Mu}$ & $N R$ & 296.6 & 16.3 & 0 & 54.3 & 0 \\
\hline $29 \mathrm{Ch}$ & NR & 484.5 & 58.0 & 0 & 235.8 & 0 \\
\hline Average & & 649.0 & 41.4 & & 87.6 & \\
\hline \multicolumn{7}{|c|}{$\begin{array}{l}\text { DSA: Designated smoking area inside the } \\
\text { venue }\end{array}$} \\
\hline 22 Ro & DSA & 50.9 & 2.3 & 1.6 & 360.3 & 3.3 \\
\hline $23 \mathrm{Al}$ & DSA & 36.7 & 5.3 & 5.3 & 782.5 & 14.5 \\
\hline $24 \mathrm{FV}$ & DSA & 33.6 & 4.0 & 4.0 & 585.8 & 11.9 \\
\hline $25 \mathrm{Ba}$ & DSA & 17.6 & 3.6 & 3.6 & 464.6 & 20.8 \\
\hline $26 \mathrm{Gu}$ & DSA & 26.3 & 4.0 & 4.0 & 422.4 & 15.2 \\
\hline $27 \mathrm{Ko}$ & DSA & 19.2 & 1.6 & 1.6 & 433.4 & 8.7 \\
\hline $28 \mathrm{Mu}$ & DSA & 102.8 & 1.0 & 1.0 & 172.7 & 1.0 \\
\hline $29 \mathrm{Ch}$ & DSA & 24.3 & 5.6 & 5.6 & 1961.6 & 23.3 \\
\hline Average & & 38.9 & 3.5 & 3.4 & 647.9 & 12.3 \\
\hline
\end{tabular}

venues and DSAs were observed to have a mean range of 1.7 to 3.5 burning cigarettes $/ \mathrm{m}^{3}$. The mean density of burning tobacco products in smoking rooms ranged from 1.2 to 12.3 per $100 \mathrm{~m}^{3}$ inside DSAs. Most of the observed venues were larger than $250 \mathrm{~m}^{3}$.

Table 2 shows the mean smoker density and $\mathrm{PM}_{2.5}$ by room type and provides the corresponding U.S.
EPA AQI rankings for air quality for particulate matter concentrations. The results show that $100 \%$ smokefree venues had the lowest mean $\mathrm{PM}_{2.5}$ concentration of $26.2 \mu \mathrm{g} / \mathrm{m}^{3}$, which corresponds to moderate levels of air quality. In contrast, non-smoking zones in venues that allowed DSAs had a mean $\mathrm{PM}_{2.5}$ concentration of $56.5 \mathrm{\mu g} / \mathrm{m}^{3}$, corresponding to unhealthy air quality.

Table 2. Summary statistics (mean \pm SD) for each venue/room category and corresponding U.S. EPA AQI rankings, by $\mathbf{P M}_{2.5}\left(\mu \mathrm{g} / \mathrm{m}^{3}\right)$ [24-hour]

\begin{tabular}{|c|c|c|c|c|c|}
\hline Smoking status & $\mathbf{N}$ & $\begin{array}{l}\text { Mean smoker } \\
\text { density }\end{array}$ & $\begin{array}{c}\text { Mean } \mathrm{PM}_{2.5} \\
\left(\mu \mathrm{g} / \mathrm{m}^{3}\right)^{2}\end{array}$ & $\begin{array}{l}\text { Median } \mathrm{PM}_{2.5} \\
\left(\mu \mathrm{g} / \mathrm{m}^{3}\right)\end{array}$ & $\begin{array}{l}\text { U.S. EPA AQI } \\
\text { ranking }\end{array}$ \\
\hline 100\% Smoke-free venue (SF) & 5 & 0 & $26.2 \pm 23.4$ & 17.3 & Moderate \\
\hline Non-smoking zones (NZ) of the venues with smoking zones & 7 & 0 & $56.5 \pm 24.2$ & 51.2 & Unhealthy \\
\hline Non-smoking room of the venue with DSA (NR) & 8 & 0 & $87.6 \pm 70.4$ & 67.1 & Unhealthy \\
\hline Smoking throughout the venue (SV) & 9 & $1.1 \pm 1.0$ & $180.3 \pm 161.3$ & 119.6 & Very unhealthy \\
\hline Smoking zones (SZ) of the venues with non-smoking zone & 7 & $1.2 \pm 1.1$ & $182.0 \pm 109.6$ & 184.0 & Very unhealthy \\
\hline Designated smoking rooms in smoke-free venues (DSA) & 8 & $12.3 \pm 7.9$ & $647.9 \pm 559.0$ & 449.0 & Hazardous \\
\hline
\end{tabular}


Figure 1. Minute-by-minute $P M_{2.5}$ levels: $100 \%$ smoke-free food-serving venues vs smoking venues with nonsmoking areas and designated smoking areas, Sept-Oct 2017

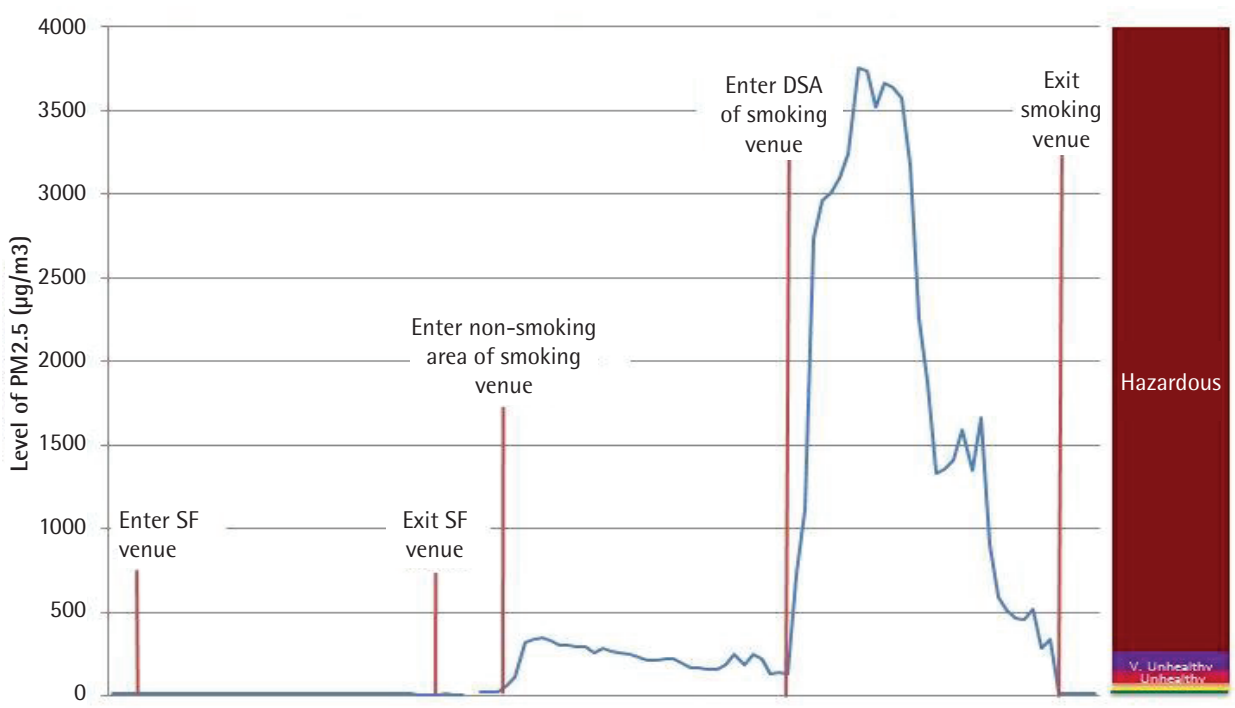

Non-smoking rooms in venues that have DSAs as separate rooms also had unhealthy air quality, with mean $\mathrm{PM}_{2.5}$ concentrations of $87.6 \mu \mathrm{g} / \mathrm{m}^{3}$. Designated smoking areas had a mean $\mathrm{PM}_{2.5}$ concentration of $647.9 \mu \mathrm{g} / \mathrm{m}^{3}$, a hazardous level of air quality, while food-serving venues with either a smoking zone or which allowed smoking throughout the venue had mean $\mathrm{PM}_{2.5}$ concentrations of $180.3-182.0 \mu \mathrm{g} / \mathrm{m}^{3}$, ranking as a very unhealthy level of air quality. The mean $\mathrm{PM}_{2.5}$ concentration for the non-smoking zones $\left(56.5 \mu \mathrm{g} / \mathrm{m}^{3}\right)$ was 2.1 times higher than the $100 \%$ smoke-free venues $\left(26.2 \mu \mathrm{g} / \mathrm{m}^{3}\right)$. The mean $\mathrm{PM}_{2.5}$ concentration level of $647.9 \mu \mathrm{g} / \mathrm{m}^{3}$ inside DSAs was 3.6 times greater than the mean $\mathrm{PM}_{2.5}$ concentration in venues that allow smoking throughout the venue $\left(180.3 \mu \mathrm{g} / \mathrm{m}^{3}\right)$ and almost 25 times higher than in smoke-free settings $\left(26.2 \mu \mathrm{g} / \mathrm{m}^{3}\right)$.

Figure 1 shows the minute-by-minute comparison of $\mathrm{PM}_{2.5}$ levels in $100 \%$ smoke-free food-serving venues compared to smoking venues with nonsmoking areas and those with designated smoking areas.

The graph indicates that inside the smoke-free food-serving venues, $\mathrm{PM}_{2.5}$ levels were consistently low. The entrances to non-smoking zones of venues that also had smoking zones had higher levels of $\mathrm{PM}_{2.5}$, ranging from approximately 200 to $300 \mu \mathrm{g} / \mathrm{m}^{3}$, which indicates unhealthy air quality. The entrance to a selected DSA had an average $\mathrm{PM}_{2.5}$ level of 3600 $\mathrm{\mu g} / \mathrm{m}^{3}$, which is 14.4 times greater than the average $\mathrm{PM}_{2.5}$ levels of the non-smoking areas of the venues.

The mean smoker density in venues where smoking was not allowed (SF, NZ, NR) was zero, unlike venues that provided smoking allowed zones and where smoking was allowed throughout the venue, which had similar values of 1.1 and 1.2 per $100 \mathrm{~m}^{3}$, respectively. DSAs had the highest mean smoker density of 12.3. Smoke-free venues (SF) have the lowest mean $\mathrm{PM}_{2.5}$ concentration of $26.2 \mu \mathrm{g} / \mathrm{m}^{3}$. The mean $\mathrm{PM}_{2.5}$ concentrations of non-smoking zones (NZ) ranged from 32.3 to $80.7 \mu \mathrm{g} / \mathrm{m}^{3}$, with an overall mean of $56.5 \mu \mathrm{g} / \mathrm{m}^{3}$. Non-smoking rooms of venues with DSAs (NR) had a mean $\mathrm{PM}_{2.5}$ concentration of $87.6 \mathrm{\mu g} / \mathrm{m}^{3}$, while DSAs in these venues had a mean of $647.9 \mu \mathrm{g} / \mathrm{m}^{3}$.

Restaurants where smoking is allowed throughout the venue (SV) or provide smoking zones (SZ) showed similar mean $\mathrm{PM}_{2.5}$ concentrations around $180.3 \mu \mathrm{g} / \mathrm{m}^{3}$. Across all room types, the mean $\mathrm{PM}_{2.5}$ concentrations ranged from the lowest value 26.2 $\mu \mathrm{g} / \mathrm{m}^{3}$ in SFs to the highest value of $647.9 \mu \mathrm{g} / \mathrm{m}^{3}$ in DSAs. Based on the U.S. EPA AQI, only smoke-free venues had moderate levels of air pollution, while other room types showed unhealthy (NZ, NR), very unhealthy (SV, SZ) or hazardous levels (DSA) of air pollution. The results of the Spearman correlation analysis indicate a strong correlation between smoker density and $\mathrm{PM}_{2.5}$ concentrations across all room types 
$(\mathrm{r}=0.80 ; \mathrm{n}=44 ; \mathrm{p}<0.01)$.

A Kruskal-Wallis $\mathrm{H}$ test was conducted to discover whether median $\mathrm{PM}_{2.5}$ concentrations were different among room types $\mathrm{SF}(5), \mathrm{NZ}(7), \mathrm{NR}(8), \mathrm{SV}(9), \mathrm{SZ}$ (7), and DSA(8). The test showed that there was a statistically significant difference in median $\mathrm{PM}_{2.5}$ concentrations across all six room types $(\mathrm{p}=0.0001)$. The Wilcoxon signed-rank test within the venues showed that the median $\mathrm{PM}_{2.5}$ concentration in smoking zones (SZ) found no difference from nonsmoking zones $(\mathrm{NZ})(\mathrm{p}=0.062)$. The same test showed that the median $\mathrm{PM}_{2.5}$ concentrations between non-smoking rooms and DSAs within the same venues are different $(p=0.01)$. The Mann-Whitney U test showed a statistically significant difference between the median $\mathrm{PM}_{2.5}$ concentrations for smoking zones and DSAs $(\mathrm{p}=0.005)$. Median $\mathrm{PM}_{2.5}$ concentrations were not found to be different between smoking zones and venues that allow smoking throughout $(\mathrm{p}=0.56)$, between non-smoking zones and non-smoking rooms of the venues with DSAs ( $\mathrm{p}=0.49)$, and between nonsmoking zones and smoke-free venues $(p=0.06)$. The Mann-Whitney U test also showed a difference in median $\mathrm{PM}_{2.5}$ concentrations between smoke-free venues and non-smoking rooms of the venues with DSAs $(p=0.02)$ and with those venues that allow smoking throughout the venue and DSAs $(p=0.01)$.

\section{DISCUSSION}

To the best of our knowledge, this is the only study of the post-Soviet countries with transitional economies that provides $\mathrm{PM}_{2.5}$ concentrations categorized by food-serving venues with different smoke-free policies, from complete smoke-free environment to those venues with designated smoking areas. Results showed that limited smoke-free policies negatively affect air quality of indoor eating places in Almaty. According to Table 2, 'moderately healthy' air quality was observed in smoke-free venues, while all other rooms in food-serving venues showed poor air quality levels. Despite the lack of tobacco burning products, non-smoking zones and non-smoking rooms in venues with DSAs showed 'unhealthy' air quality levels based on the U.S. EPA AQI Rankings for $\mathrm{PM}_{2.5}$. Venues were smoking is allowed throughout and venues with smoking zones had air quality ranked as 'very unhealthy'. The poorest air quality was measured in DSAs, corresponding to 'hazardous' levels. The highest density of people and the smallest volumes for rooms were observed for DSAs, where air quality was hazardous for human health.

According to our findings, the implementation of separate smoking zones or DSAs does not substantially improve air quality inside food-serving venues. The mean $\mathrm{PM}_{2.5}$ concentrations in the non-smoking zone and non-smoking room in venues with DSAs are unhealthy and are more than two times and three times higher than in smoke-free venues, respectively. Wilcoxon test helped to establish the difference in median $\mathrm{PM}_{2.5}$ concentrations between smoking zone and non-smoking zones of the venue. This indicates that food-serving venues that have separate zones for smokers and non-smokers do not substantially protect the non-smokers from secondhand smoke. Comparison of the median $\mathrm{PM}_{2.5}$ concentrations between non-smoking zones and non-smoking rooms in venues with DSAs showed no statistical differences. This also indicates that DSAs also do not substantially protect non-smokers from secondhand smoke. $\mathrm{PM}_{2.5}$ concentrations in DSAs are 3.5 times higher than in venues where smoking is allowed throughout the venue. These findings indicate that DSAs do not protect employees and non-smoking patrons from exposure to unhealthy air quality.

Results suggest that the substantial part of $\mathrm{PM}_{2.5}$ concentrations are due to cigarette and/or hookah smoking. Our findings determined that the higher the smoker density the poorer the air quality in the venue.

The results of the study are consistent with those from other publications that analyzed air quality levels of hospitality venues by measuring particulate matter under diverse smoking policies. The analysis of 95 hospitality venues in Switzerland, showed four times higher concentrations of $\mathrm{PM}_{2.5}$ in non-smoking rooms than in smoke-free environments, despite separation of smokers from non-smokers ${ }^{21}$. In Sydney, a study of 17 gaming clubs comparing $\mathrm{PM}_{2.5}$ concentrations in designated smoking areas with non-smoking areas found that non-smoking areas still had almost half of the particulate matter concentrations of the designated smoking areas. The study concluded that DSAs provide limited to no protection from secondhand smoke ${ }^{10}$.

\section{Limitations}

Two limitations are present in the study. First, we 
had observed only 29 places of Almaty due to time constraints and financial restrictions. Although we had covered all possible variations of existing smokefree policy, such research should be done in other big cities to be able to generalize results to the whole country. The second limitation is the presence of both cigarettes and hookahs at the observation sites. Thus, it is not clear which tobacco product contributed most to the air pollution inside the venues. However, this limitation is difficult to avoid due to the mixture of smoke as most venues propose both hookahs and cigarettes to patrons.

\section{CONCLUSIONS}

Smoking policies for food-serving venues that allow designated smoking areas are ineffectual in protecting people from secondhand tobacco smoke exposure. Non-smoking rooms in venues with DSAs had two times higher air pollution levels than smoke-free venues. A smoke-free policy in venues is the only way to effectively protect non-smokers from secondhand smoke in hospitality settings. Non-smoking zones and venues that were compliant to the law and restricted smoking to DSAs only, had unhealthy air quality in non-smoking areas and hazardous levels of $\mathrm{PM}_{2.5}$ inside DSAs due to tobacco products. It proves the low efficiency of a smoking ban with exemptions. Complete smoking ban in food-serving venues should be in place to fully protect people from hazardous air quality conditions in Kazakhstan.

\section{REFERENCES}

1. Frazer K, Callinan JE, McHugh J, et al. Legislative smoking bans for reducing harms from secondhand smoke exposure, smoking prevalence and tobacco consumption. Cochrane Database Syst Rev. 2016(2). doi:10.1002/14651858.CD005992.pub3

2. World Health Organization, International Agency for Research on Cancer. Tobacco smoke and involuntary smoking. IARC Monographs on the Evaluation of Carcinogenic Risks to Humans Volume 83. Lyon, France: International Agency for Research on Cancer; 2004.

3. International Agency for Research on Cancer, World Health Organization. Methods for Evaluating Tobacco Control Policies. IARC Handbooks of Cancer Prevention Volume 12. Lyon, France: International Agency for Research on Cancer; 2008.

4. International Agency for Research on Cancer, World Health Organization. Evaluating the Effectiveness of Smoke-free Policies. IARC Handbooks of Cancer
Prevention, Tobacco Control, Vol. 13. Lyon, France: International Agency for Research on Cancer; 2009.

5. Öberg M, Jaakkola M, Woodward A, Peruga A, PrüssUstün A. Worldwide burden of disease from exposure to second-hand smoke: a retrospective analysis of data from 192 countries. Lancet. 2011;377(9760):139-146. doi:10.1016/s0140-6736(10)61388-8

6. Abdrakhmanova S, Keruyenova Z. The Current State of MPOWER Policies in the Republic of Kazakhstan: Data from the Global Adult Tobacco Survey 2014. Iran J Public Health. 2019;48(5):834-840. doi:10.18502/ijph.v48i5.1799

7. Sadykova J, Kalmatayeva Z. Smoking rooms undermine FCTC agenda in Kazakstan. Tob Induc Dis. 2018;16(Supplement 1:A436). doi:10.18332/tid/84713

8. Code of the Republic of Kazakhstan. [Prevention and restriction of the consumption of tobacco products and alcohol]. Article 159. https://online.zakon.kz/ document/?doc_id=30479065\#pos=4311;-61. Published September 18, 2009. Updated April 6, 2015. Accessed April 12, 2019.

9. Lambert W, Samet J, Spengler J. Environmental tobacco smoke concentrations in no-smoking and smoking sections of restaurants. Am J Public Health. 1993;83(9):1339-1341. doi:10.2105/ajph.83.9.1339

10. Cains T, Cannata S, Poulos R, Ferson MJ, Stewart BW. Designated 'no smoking' areas provide from partial to no protection from environmental tobacco smoke. Tob Control. 2004;13:17-22. doi:10.1136/tc.2003.005488

11. New Jersey Department of Environmental Protection. 2017 Air Quality Index. http://njaqinow.net/App_ Files/2017/AQI\%202017.pdf. Accessed May 18, 2020.

12. Travers M, Cummings K, Hyland A, et al. Indoor Air Quality in Hospitality Venues Before and After Implementation of a Clean Indoor Air Law. Oncology Times. 2004;26(23):5255. doi:10.1097/01.cot.0000291669.36813.6f

13. Lee K, Hahn E, Robertson H, Lee S, Vogel S, Travers M. Strength of smoke-free air laws and indoor air quality. Nicotine Tob Res. 2009;11(4):381-386. doi:10.1093/ntr/ntp026

14. Kaufman P, Zhang B, Bondy S, Klepeis N, Ferrence R. Not just 'a few wisps': real-time measurement of tobacco smoke at entrances to office buildings. Tob Control. 2010;20(3):212-218. doi:10.1136/tc.2010.041277

15. Hyland A, Travers M, Dresler C, Higbee C, Cummings K. A 32-country comparison of tobacco smoke derived particle levels in indoor public places. Tob Control. 2008;17(3):159-165. doi:10.1136/tc.2007.020479

16. Waring M, Siegel J. An evaluation of the indoor air quality in bars before and after a smoking ban in Austin, Texas. J Expo Sci Environ Epidemiol. 2006;17(3):260-268. doi:10.1038/sj.jes.7500513

17. Republic of Kazakhstan - Almaty City: Administrations structure. https://www.almaty.gov.kz/page.php?page_ $\mathrm{id}=338 \&$ lang $=2$. Published 2018. Accessed August 17, 2018.

18. Cobb C, Vansickel A, Blank M, Jentink K, Travers M, Eissenberg 
T. Indoor air quality in Virginia waterpipe cafés. Tob Control. 2012;22(5):338-343. doi:10.1136/tobaccocontrol-2011-050350

19. Jones S, Love C, Thomson G, Green R, Howden-Chapman P. Second-hand smoke at work: The exposure, perceptions and attitudes of bar and restaurant workers to environmental tobacco smoke. Aust N Z J Public Health. 2001;25(1):9093. doi:10.1111/j.1467-842x.2001.tb00557.x

20. Lee K, Hahn EJ, Pieper N, Okoli CT, Repace J, Troutman A. Differential impacts of smoke-free laws on indoor air quality. J Environ Health. 2008;70(8):24-30,54. PMID: 18468220

21. Huss A, Kooijman C, Breuer M, et al. Fine particulate matter measurements in Swiss restaurants, cafés and bars: what is the effect of spatial separation between smoking and non-smoking areas? Indoor Air. 2010;20(1):52-60. doi:10.1111/j.1600-0668.2009.00625.x
ACKNOWLEDGEMENTS

The research team highly appreciates the input of the principal observer, Skatova Alexandra, the technical support from faculty members of Nazarbayev University, and the Smoke-free Kazakhstan coalition.

\section{CONFLICTS OF INTEREST}

The authors have each completed and submitted an ICMJE form for disclosure of potential conflicts of interest. The authors declare that they have no competing interests, financial or otherwise, related to the current work. J. Sadykova and A. Baizhaxynova report a non-financial support from the American non-profit membership organization Campaign for Tobacco-Free Kids, during the conduct of the study.

\section{FUNDING}

This work was supported by Kazakhstan Smoke-free coalition and the Campaign for Tobacco-Free Kids, which provided the trainer and TSI SidePak AM510.

\section{AUTHORS' CONTRIBUTIONS}

All authors contributed in composing, editing and critical analyzing the content of the manuscript. The manuscript was read and approved by all authors. JS justified the need of air monitoring research and obtained funding from TFK, designed and planned the study, participated as team observer, analyzed and interpreted the data, drafted and jointly edited the manuscript. $A B$ analyzed and interpreted the data with statistical methods, drafted the first manuscript with further joint editing until the final version of the manuscript. BC edited and critically analyzed the manuscript, proofread and made ongoing and final editing.

PROVENANCE AND PEER REVIEW

Not commissioned; externally peer reviewed. 